\title{
Evisceração decorrente de orquiectomia na espécie equina: relato de caso
}

\author{
Breno Curty Barbosa ${ }^{1}$, Tatiany Luiza Silveira $^{2}$, Ingrid Bromerschenkel ${ }^{3}$, Thomas \\ Alexander Trein ${ }^{4}$, Eduardo de Magalhães Panelli ${ }^{5}$, Eugenio Nardin Neto ${ }^{5}$, Flavia de \\ Almeida Lucas ${ }^{5}$
}

${ }^{I}$ Doutorando em Ciência Animal - Escola de Veterinária - UFMG, Belo Horizonte, MG.

${ }^{2}$ Doutoranda em Patologia - Faculdade de Medicina - UFMG, Belo Horizonte, MG.

${ }_{3}$ Doutoranda em Medicina Veterinária - Faculdade de Ciências Agrárias e Veterinárias - UNESP - Jaboticabal, SP.

${ }^{4}$ Médico veterinário Autônomo

${ }^{5}$ Departamento de Clínica e Cirurgia Animal - Faculdade de Medicina Veterinária - UNESP - Araçatuba, SP.

*Autor para correspondência: brenocurty@hotmail.com

\begin{abstract}
RESUMO. O presente relata a evisceração e posterior herniação inguinal de segmento de jejuno em equino submetido à orquiectomia. Um eqüino da raça Mangalarga Marchador, macho, 15 anos, foi encaminhado para realização de orquiectomia eletiva em haras no município de Alegre-ES. Após sedação e anestesia local, o paciente foi submetido ao procedimento cirúrgico. Decorridos 15 minutos, foi observado sangramento na região da bolsa escrotal, com visualização de tecido emergindo da ferida cirúrgica na bolsa escrotal direita. Após exame visual verificou-se tratar de porção do intestino delgado insinuandose pelo anel inguinal e ferida cirúrgica. Imediatamente o paciente foi submetido à laparotomia mediana à campo para redução da evisceração, sob anestesia geral intravenosa. $\mathrm{O}$ redução foi realizada com êxito, com sutura do anel inguinal externo direito. Decorridas seis horas do término da laparotomia, o paciente apresentou quadro clinico de abdômen agudo, e à palpação retal constatou-se presença de hérnia inguinal direita. Optou-se pela eutanásia do animal, por não haver um centro cirúrgico de grandes animais na região. Na necropsia foi verificado porção de jejuno insinuada no canal inguinal direito, com estrangulamento, apresentando-se com coloração esverdeada. A orquiectomia é uma técnica de execução relativamente simples, podendo ser realizada a campo pelo médico veterinário, porém, apresenta taxas de complicações elevadas, entre 20 a $38 \%$ dos casos, principalmente associados a erros de técnica cirúrgica. A evisceração intestinal pós-castração é considerada uma situação de emergência, exigindo uma conduta terapêutica rápida e eficiente. A sua ocorrência é rara, em torno de 0,2 a 2,6 \% dos casos de orquiectomia. A palpação retal prévia à orquiectomia pode auxiliar na detecção de um anel inguinal interno dilatado ou qualquer alteração no mesmo, todavia esta prática não é realizada rotineiramente no pré-operatório de orquiectomia na espécie eqüina.
\end{abstract}

Palavras chave: equinos, castração, evisceração

\section{Evisceration in a horse submitted to orchiectomy: a case report}

\begin{abstract}
This case report describes an evisceration of a segment of the small intestine in a male, 15-years-old Mangalarga Marchador horse, which was submitted to elective orchiectomy in a stud farm in Alegre, ES, Brazil. Following sedation and local anesthesia, the patient was submitted to the surgical procedure. Fifteen minutes after the end of surgery, hemorrhage from the region of the scrotum was observed, with tissue protruding from the surgical wound in the right scrotal sac. Visual exam revealed that it was a segment of the small intestine protruding from the inguinal ring and surgical wound. The patient was immediately submitted to TIVA (total intravenous anesthesia) and an emergency median laparotomy was performed to reduce the evisceration. The procedure was carried out with success and the right external inguinal ring was sutured. Six hours after the second procedure, the patient presented clinical signs of acute
\end{abstract}


abdomen, and rectal palpation revealed a right inguinal hernia. It was decided to perform euthanasia of the animal as there was no referral large animal surgery center in the region. During necropsy, a segment of the jejunum insinuated in the right inguinal canal was observed, evidencing strangulation and a greenish appearance. Orchiectomy is a relatively simple technique to execute, which can be performed by the veterinary surgeon in the field. However, it presents elevated rates of complications, ranging from 20 to $38 \%$ of the cases, which are predominantly associated to surgical technique errors. Intestinal evisceration following orchiectomy is considered an emergency situation, requiring a fast and efficient therapeutic conduct. Its incidence is rare, occurring in between 0.2 and $2.6 \%$ of the cases of orchiectomy. It is believed that rectal palpation prior to orchiectomy could aid in the detection of a dilated internal inguinal ring, or any other alteration in this structure. Nevertheless, this practice is not performed pre-operatively in cases of orchiectomy in the equine species.

Keywords: equines, orchiectomy, evisceration.

\section{Introdução}

A orquiectomia a é uma técnica rotineira na criação de equinos e é recomendado em pacientes com idade entre 1-2 anos (Shoemaker et al., 2004, Kummer et al., 2009).

É de execução relativamente simples, podendo ser realizada a campo pelo médico veterinário. Apresenta taxas de complicações elevadas, entre 20 a $38 \%$ dos casos, principalmente associados a erros de técnica cirúrgica. Dentre as principais complicações citam-se a formação de edema, hemorragia extensa, herniações, tanto do omento quanto de porções intestinais, peritonite, infecções, traumas peniano e evisceração, entre outros (Shoemaker et al., 2004). Estas complicações podem ser minimizadas se a orquiectomia for realizada em um centro cirúrgico, com todas as técnicas de assepsia e anti-sepsia obedecidas (Mason et al., 2005, Getman \& White, 2009). Todavia, na rotina veterinária de eqüinos, é um procedimento realizado, em sua grande maioria, a campo. A taxa de ocorrência pós-orquiectomia é relativamente baixa, em torno de 0,2 a 2,6 \% dos casos. Entretanto, quando ocorre, é de difícil resolução, e quase sempre leva o paciente à óbito. A insinuação das alças intestinais pelo anel inguinal pode ocorrer em até 4 horas após o procedimento, sendo relatados casos de até 12 dias após a cirurgia. Fatores predisponentes são: hérnia inguinal incipiente prévia à cirurgia, determinadas maior em determinadas raças, além do aumento do diâmetro do anel inguinal interno, posição do animal durante a realização do procedimento e técnica escolhida (Schumacher, 1992).

Com este relato, objetivou-se descrever a ocorrência de evisceração após orquiectomia eletiva na espécie equina, salientando a importância de rápida intervenção para a sua correção, bem como a necessidade de infraestrutura adequada para o sucesso no tratamento.

\section{Relato de caso}

O paciente, um equino macho, com 15 anos de idade, da raça Mangalarga marchador, foi submetido à orquiectomia bilateral eletiva na sua propriedade de origem, no município de Alegre, ES. O animal, previamente em jejum hídrico e alimentar de 6 e 12 horas, respectivamente, recebeu sedação com xilazina a $2 \%\left(1 \mathrm{mg} \mathrm{kg}^{-1}\right)$, seguida por infusão de Éter gliceril guaiacol ${ }^{b}$ $\left(100 \mathrm{mg} \mathrm{kg}^{-1}\right)$ e tiopental sódico ${ }^{\mathrm{c}}$ (2 gramas), todos pela via intravenosa. $\mathrm{O}$ paciente foi colocado em decúbito lateral esquerdo e o membro pélvico foi tracionado caudalmente e elevado para possibilitar o acesso do cirurgião à bolsa escrotal. Decorridos 10 minutos da realização de bloqueio local com lidocaína ${ }^{\mathrm{d}} 2 \%$ com vasoconstritor intratesticular $(15 \mathrm{ml} \mathrm{em}$ cada testículo), uma incisão da pele paralela à rafe mediana, de aproximadamente $8 \mathrm{~cm}$ foi realizada, atingindo as túnicas dartos e albugínea para exposição do testículo. Ato contínuo seccionouse o ligamento da cauda do epidídimo, liberando a túnica parietal e músculo cremáster, individualizando o cordão espermático e ducto deferente, que foram ligados utilizando-se fio de poliglactina ${ }^{\mathrm{e}} 910$ no. 2. A mesma técnica foi utilizada para a exérese do testículo contralateral. Nenhuma intercorrência foi observada durante procedimento cirúrgico. Ao término da cirurgia, o paciente retornou da anestesia, permanecendo em estação dentro de 20 minutos, sendo então encaminhado à baia. Decorridos 15 minutos, foi observado um pequeno sangramento 
na região da bolsa escrotal, com visualização de tecido emergindo da ferida cirúrgica da bolsa escrotal direita. Após exame visual, verificou tratar-se de porção do intestino delgado insinuando-se pelo anel inguinal e ferida cirúrgica (Figura 1).

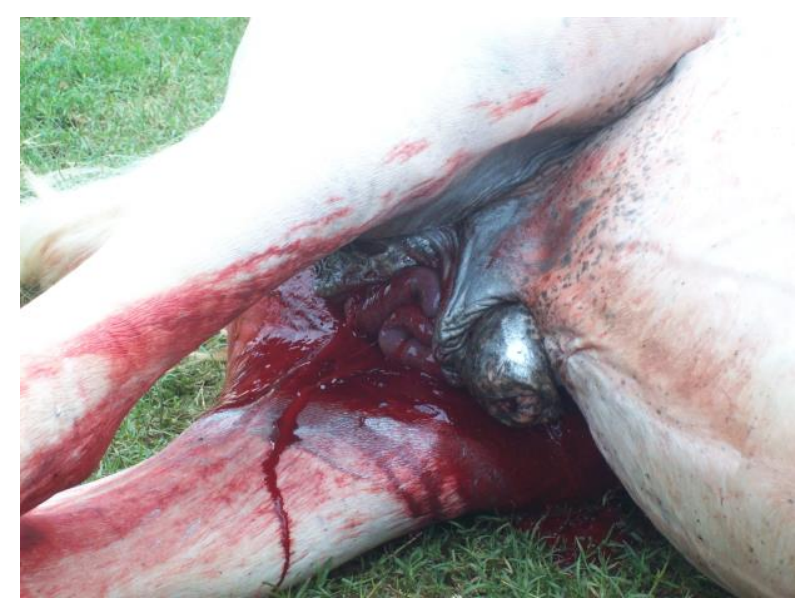

Figura 1. Imagem fotográfica ilustrando a evisceração de intestino delgado pós-orquiectomia em equino. $\mathrm{Na}$ imagem, o animal encontrava-se anestesiado e sendo preparado para a correção da evisceração.

Imediatamente o paciente foi submetido à anestesia geral intravenosa (TIVA) para tentativa do retorno do segmento exposto para a cavidade abdominal pelo canal inguinal, porém sem sucesso. Na sequência, uma laparotomia mediana de emergência foi necessária para reduzir a evisceração. $\mathrm{O}$ procedimento foi realizado com êxito, a alça foi recolocada dentro da cavidade abdominal e o anel inguinal externo direito foi suturado com fio poliglactina 910 no. 2 e padrão de sutura sultan. A laparotomia foi fechada de maneira rotineira. Iniciou-se no pós-operatório imediato terapia antiinflamatória com flunixin meglumine $^{\mathrm{f}}\left(1 \mathrm{mg} \mathrm{kg}^{-1}\right.$, SID) e antimicrobiana com penicilina ${ }^{\mathrm{g}} \quad(40.000 \mathrm{UI} / \mathrm{kg}, \quad$ BID) $\mathrm{e}$ metronidazol $^{\mathrm{h}}$ (15 mg kg ${ }^{-1}$, BID). $\mathrm{O}$ animal retornou da anestesia sem complicações e foi novamente encaminhado à baia. Após seis horas, o paciente iniciou quadro clinico de abdômen agudo, e à palpação retal constatou-se a presença de alça intestinal no anel inguinal direito. Devido a indisponibilidade financeira e de infra-estrutura e diante de eminente quadro de choque, optou-se pela eutanásia do animal e necropsia subsequente. $\mathrm{Na}$ abertura da cavidade abdominal observou-se o liquido peritoneal turvo e de coloração avermelhada, a serosa do intestino delgado com coloração vermelho escuro e os vasos mesentéricos engurgitados. Foi constatado que uma pequena porção do jejuno encontrava-se de coloração enegrecida e insinuada no canal inguinal direito e, após a dissecação do canal notou-se estrangulamento e torção do seguimento herniado com necrose do mesmo.

\section{Discussão}

A etiologia envolvida na evisceração pósorquiectomia é multifatorial, incluindo o tamanho do anel inguinal, o posicionamento do membro pélvico durante o procedimento cirúrgico, aumento da pressão intra-abdominal e a técnica escolhida. A elevação da pressão intra-abdominal tem sido considerada um importante fator nos casos de evisceração pós-orquiectomia e está associada à técnica cirúrgica eleita, visto que observa-se maior ocorrência em orquiectomia aberta. Nesta técnica, a abertura da túnica vaginal acarreta uma comunicação do meio externo com a cavidade abdominal aumentando, assim, o fluxo de ar para o interior da mesma e elevando a sua pressão. A técnica fechada evita esta comunicação (Thomas et al., 1998, Shoemaker et al., 2004, Carmalt et al., 2008).

Os membros pélvicos flexionados durante o procedimento e na recuperação anestésica e decorrente do decúbito e técnica cirúrgica eleitos para a orquiectomia deste animal são fatores predisponentes à evisceração, sobretudo se a técnica aberta for a escolhida, aumentando desta forma a pressão intra-abdominal (Thomas et al., 1998, Searle et al., 1999).

Outros fatores como animais com até seis meses de idade, tempo de exercício pósoperatório e hérnia inguinal pré-existente também elevam a chance de ocorrência de evisceração. Animais jovens com menos de seis meses podem apresentar hérnia inguinal congênita, estando mais predispostos à ocorrência de evisceração após a orquiectomia. Equinos submetidos a exercícios físicos após 24 horas do procedimento também são mais propensos ao quadro (Schumacher, 1992), sendo que o exercício aumentaria o diâmetro do anel inguinal interno, ficando o animal predisposto à evisceração.

$\mathrm{O}$ garanhão submetido à orquiectomia neste relato contava com 15 anos de idade e não era submetido a exercícios regulares, por não tratarse de um animal atleta, além de não estar mais ativo na cobertura de éguas, excluindo-se assim os fatores idade e exercícios ao quadro de evisceração. Por outro lado, foi submetido ao decúbito lateral para a realização do 
procedimento, além de escolhida a técnica aberta para o mesmo. Provavelmente, o decúbito lateral e o tracionamento do membro pélvico aumentaram o diâmetro do anel inguinal interno, possibilitando a passagem de alças de intestino delgado pelo canal inguinal e a abertura da túnica vaginal (técnica aberta) permitiu a exteriorização das alças intestinais. Após a correção da evisceração via laparotomia de emergência, mesmo com o fechamento do anel inguinal externo, houve passagem de alça pelo anel inguinal interno, ocasionando a herniação da mesma.

Acredita-se que a palpação retal prévia à orquiectomia associado com a palpação dos testículos e bolsa escrotal poderia auxiliar na detecção de um anel inguinal interno dilatado ou qualquer alteração no mesmo, todavia esta prática não é realizada no pré-operatório de orquiectomia na espécie equina, além de não necessariamente indicar ou prever algum problema futuro. Apesar de recomendado, este procedimento apresenta limitações, pois, a padronização do tamanho do anel não está bem discutido na literatura para comparação e ainda torna-se difícil uma determinação exata da largura do anel inguinal detectada na palpação, sendo este dado apenas subjetivo, onde a experiência do cirurgião prevalece (Searle et al., 1999, Shoemaker et al., 2004). No presente relato, não foi realizada a palpação prévia visando detectar alterações prévias no anel inguinal interno, visto que o animal era saudável, com histórico de coberturas durante sua vida reprodutiva, sem quaisquer intercorrências.

\section{Conclusão}

A orquiectomia na espécie equina, considerada um procedimento simples e de rotina, pode evoluir com complicações de extrema gravidade, como a evisceração, devendo o médico veterinário estar atento as mesmas e, dentro do possível, indicar a sua realização em centros especializados no atendimento equino.

\section{Fontes de aquisição}

a. Rompum - Bayer S.A. Saúde Animal, São Paulo, SP, Brasil.

b. Éter gliceril guaiacol. Henryfarma. São Paulo, SP, Brasil.

c. Thiopentax. Cristália. São Paulo, SP, Brasil.

d. Xylestesin. Cristália. São Paulo, SP, Brasil. e. Vicryl. Ethicon. São José dos Campos, SP, Brasil.

f. Flunixin injetável. Chemitec. São Paulo, SP, Brasil.

g. Pencivet plus. MSD Saúde Animal. Cotia, SP, Brasil.

h. Metronidazol. SEM S/A. Hortolândia, SP, Brasil.

\section{Referências Bibliográficas}

Carmalt, J. L., Shoemaker, R. W. \& Wilson, D. G. (2008). Evaluation of common vaginal tunic ligation during field castration in draught colts. Equine Veterinary Journal, 40, 597-598.

Getman, L. M. \& White, N. (2009). Review of castration complications: strategies for treatment in the field. Proceedings of the 55th Annual Convention of the American Association of Equine Practitioners. American Association of Equine Practitioners, Las Vegas, Nevada, USA.

Kummer, M., Gygax, D., Jackson, M., Bettschart-Wolfensberger, R. \& Fürst, A. (2009). Results and complications of a novel technique for primary castration with an inguinal approach in horses. Equine Veterinary Journal, 41, 547-551.

Mason, B. J., Newton, J. R., Payne, R. J. \& Pilsworth, R. C. (2005). Costs and complications of equine castration: a UK practice-based study comparing 'standing nonsutured'and 'recumbent sutured'techniques. Equine Veterinary Journal, 37, 468-472.

Schumacher, J. (1992). Surgical disorders of the testicle and associated structures. Equine Surgery, 1, 674-703.

Searle, D., Dart, A. J., Dart, C. M. \& Hodgson, D. R. (1999). Equine castration: review of anatomy, approaches, techniques and complications in normal, cryptorchid and monorchid horses. Australian Veterinary Journal, 77, 428-434.

Shoemaker, R., Bailey, J., Janzen, E. \& Wilson, D. G. (2004). Routine castration in 568 draught colts: incidence of evisceration and omental herniation. Equine Veterinary Journal, 36, 336-340.

Thomas, H. L., Zaruby, J. F., Smith, C. L. \& Livesey, M. A. (1998). Postcastration 
eventration in 18 horses: the prognostic indicators for long-term survival (1985-1995). The Canadian Veterinary Journal, 39, 764768.

Article History:

Received 19 April, 2016

Accepted 12 May, 2016

Available online 24 June, 2016
License information: This is an open-access article distributed under the terms of the Creative Commons Attribution License, which permits unrestricted use, distribution, and reproduction in any medium, provided the original work is properly cited 